\title{
The Moorish gecko, Tarentola mauritanica Linnaeus, 1758 (Squamata, Phyllodactylidae), in Albania
}

\author{
Márton Szabolcs ${ }^{1}$, Edvárd Mizsei ${ }^{2}$, Aleksander Golemaj $^{3}$, Daniel Jablonski ${ }^{4}$ \\ 1 Department of Tisza River Research, Institute of Aquatic Ecology, Centre for Ecological Research, Bem tér 18/C, Debrecen 4026, Hungary \\ 2 Department of Ecology, University of Debrecen, Egyetem tér 1, Debrecen 4032, Hungary \\ 3 Lagja 29 Nëntori, Rruga Sadik Zotaj, Vlorë, Albania \\ 4 Department of Zoology, Comenius University in Bratislava, Mlynská dolina, Ilkovičova 6, Bratislava 842 15, Slovakia
}

http://zoobank.org/40EB9D6F-D84C-4763-93F6-53A14BB0BEA8

Corresponding authors: Márton Szabolcs (szabolcs.marci@gmail.com), Daniel Jablonski (daniel.jablonski@uniba.sk)

Academic editor: Günter Gollmann • Received 29 May 2021 • Accepted 22 June 2021 • Published 4 August 2021

\begin{abstract}
We summarised the records of Tarentola mauritanica in Albania. The first record for the country was published in 1989 from Sazan Island; however, it was never confirmed again. Another population was found recently in an urban habitat of Vlorë City near the main city port, probably of human-mediated origin.
\end{abstract}

\section{Key Words}

Balkan Peninsula, distribution, faunistics, introduced species, Mediterranean, reptile

Lying on the western edge of the Balkan Peninsula, Albania has a large herpetological diversity with 42 reptile (Mizsei et al. 2017) and 16 amphibian species (Szabolcs et al. 2017). Due to the geological complexity of the Dinarides and Hellenides that meet in Albania, the country harbours mountain-dwelling cold-adapted species, as well as common European species, but most of its herpetofauna is comprised of Mediterranean species including Balkan endemics (Džukić and Kalezić 2004, Speybroeck et al. 2016).

The Moorish gecko (Tarentola mauritanica Linnaeus, 1758) is a widespread lizard in the Mediterranean region of Europe and North Africa (Fig. 1A), but with a low level of genetic variability across Europe (Rato et al. 2016), which might indicate an introduced origin in at least some parts of its range (Mačát et al. 2014). In the Balkan Peninsula, it lives in isolated populations in Zadar and Hvar in Croatia (Lisičić et al. 2012) and various locations in Greece (Mačát et al. 2014, Strachinis et al. 2020). It is known from a single observation from Slovenia (Portorož, Krofel et al. 2009) and from a dubious sighting from Montenegro
(Ada Bojana, Ljubisavljević et al. 2018). It also lives just outside the Balkans in Trieste, Italy (Krofel et al. 2009). The only record for Albania comes from Sazan Island in the Adriatic Sea (Bruno 1989) (Fig. 1B, C).

We thoroughly reviewed the literature on the amphibians and reptiles from Albania to summarise and update the knowledge of their distribution patterns in the country (Mizsei et al. 2017, Szabolcs et al. 2017). Currently we are maintaining a database called Balkan Herps where everyone can upload distribution records of every herp species from the Balkan Peninsula (https://openbiomaps.org/projects/balkanherps/). An observation record of $T$. mauritanica was uploaded to the database by one of the authors (AG), broadening our knowledge of this species for Albania. To confirm this observation, we conducted two field trips and obtained new data.

Tarentola mauritanica was firstly mentioned from Albania by Bruno (1989) in his synthesising work on the country's herpetofauna where he published many other new amphibian and reptile records as well. A specimen was sent to him by E. Frommhold in 1962 from Sazan Island in the 


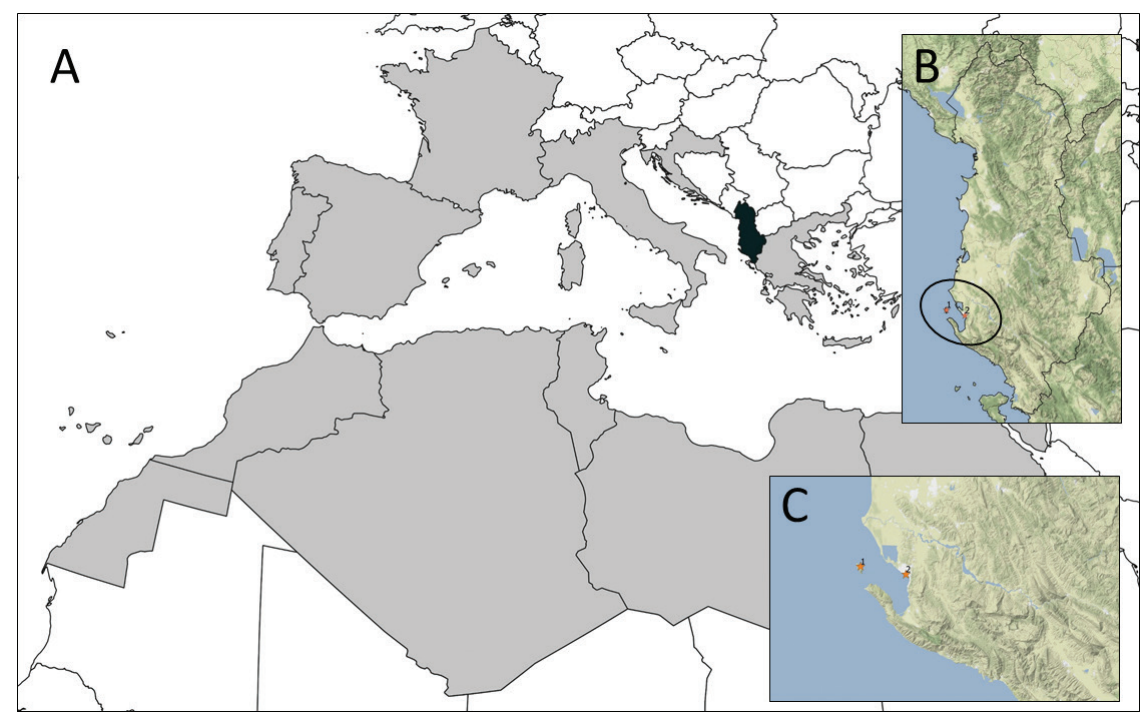

Figure 1. A. The World distribution by countries of Tarentola mauritanica, where Albania is indicated with black, while the other countries with grey; B. The locations where the species were found in Albania, with 1 indicating Sazan Island and 2 indicating Vlorë; C. A closer look at the two locations.

Adriatic Sea (Fig. 1B, C, $40.4999^{\circ} \mathrm{N}, 19.2834^{\circ} \mathrm{E}$, obtained from Google Maps). The late S. Bruno's collection is curated at the Museum of Rovereto, Italy (Fondazione Museo Civico Rovereto). We searched the Museum's online database (https://www.fondazionemcr.it/extendedsearch_museo.jsp?id_schema $=70 \& I D \_L I N K=113757 \&$ area $=295$ ), but we did not find the specimen, thus we assume it was lost during the years. Unfortunately, no-one has confirmed the presence of this species in Sazan again. The Island serves as a military base and is only accessible occasionally for civilian visitors. In 2012 and 2013, field missions were carried out to gather information on the Island's bio- diversity and to investigate the potential to designate Sazan as a protected area (Tomás-Vives 2015). They found one amphibian and eight reptile species including the Turkish gecko (Hemidactylus turcicus), but not T. mauritanica .

The second finding of T. mauritanica in Albania came from 14 March 2019 when a population was discovered in the port city of Vlorë by one of the authors (Fig. 1B, C). The observation was later confirmed by the other authors on 21 May 2019 and 10 August 2019. During the first visit, we only found geckos on a single wall made from concrete blocks, about two metres tall and $50 \mathrm{~m}$ long (Fig. 2A-D). Above the wall, there was
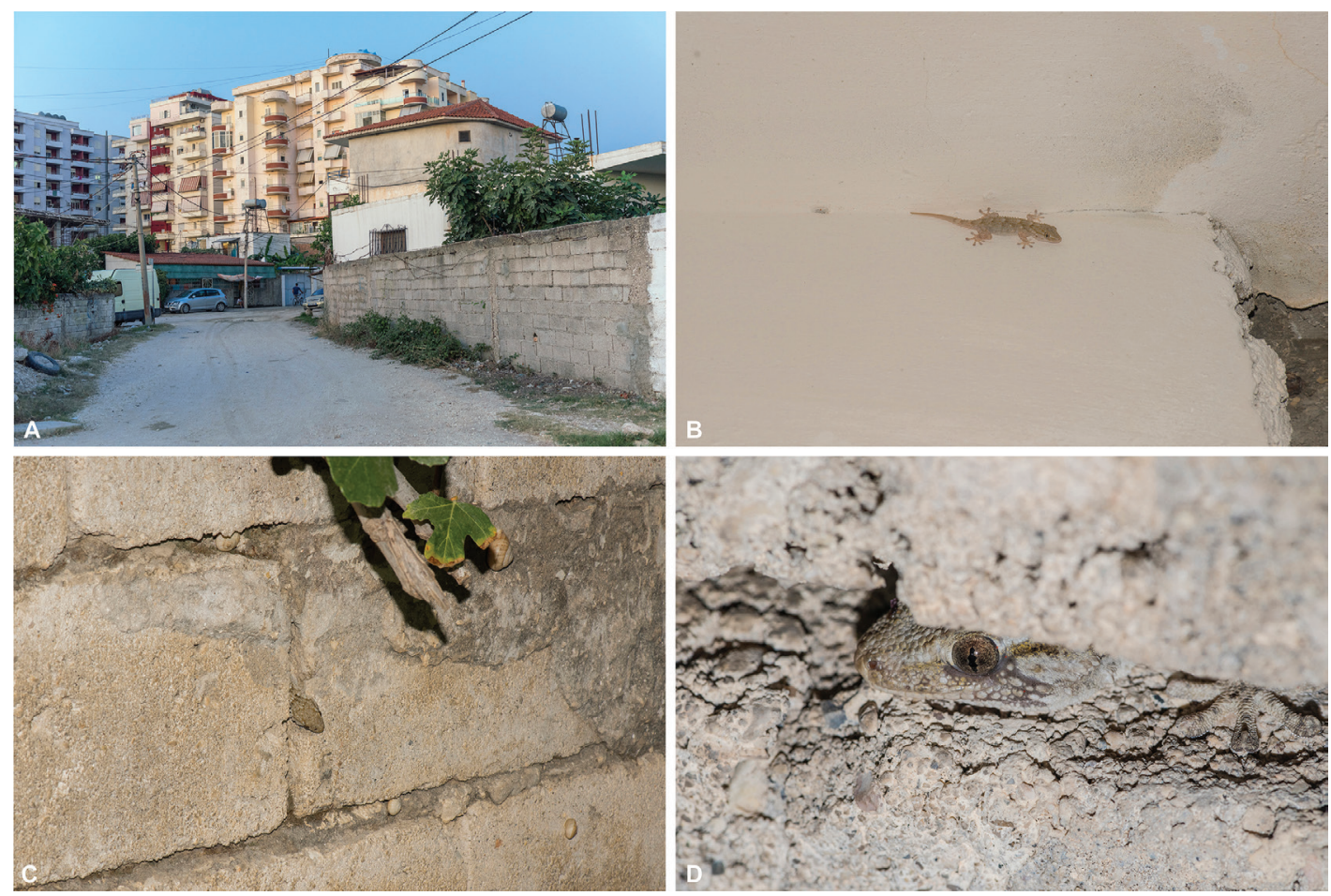

Figure 2. A. An overview of the locality and the habitat of Tarentola mauritanica population in Vlorë; B. Adult individual of T. mauritanica in situ on the wall of the house; C., D. Adult individuals in situ hiding in the wall. 

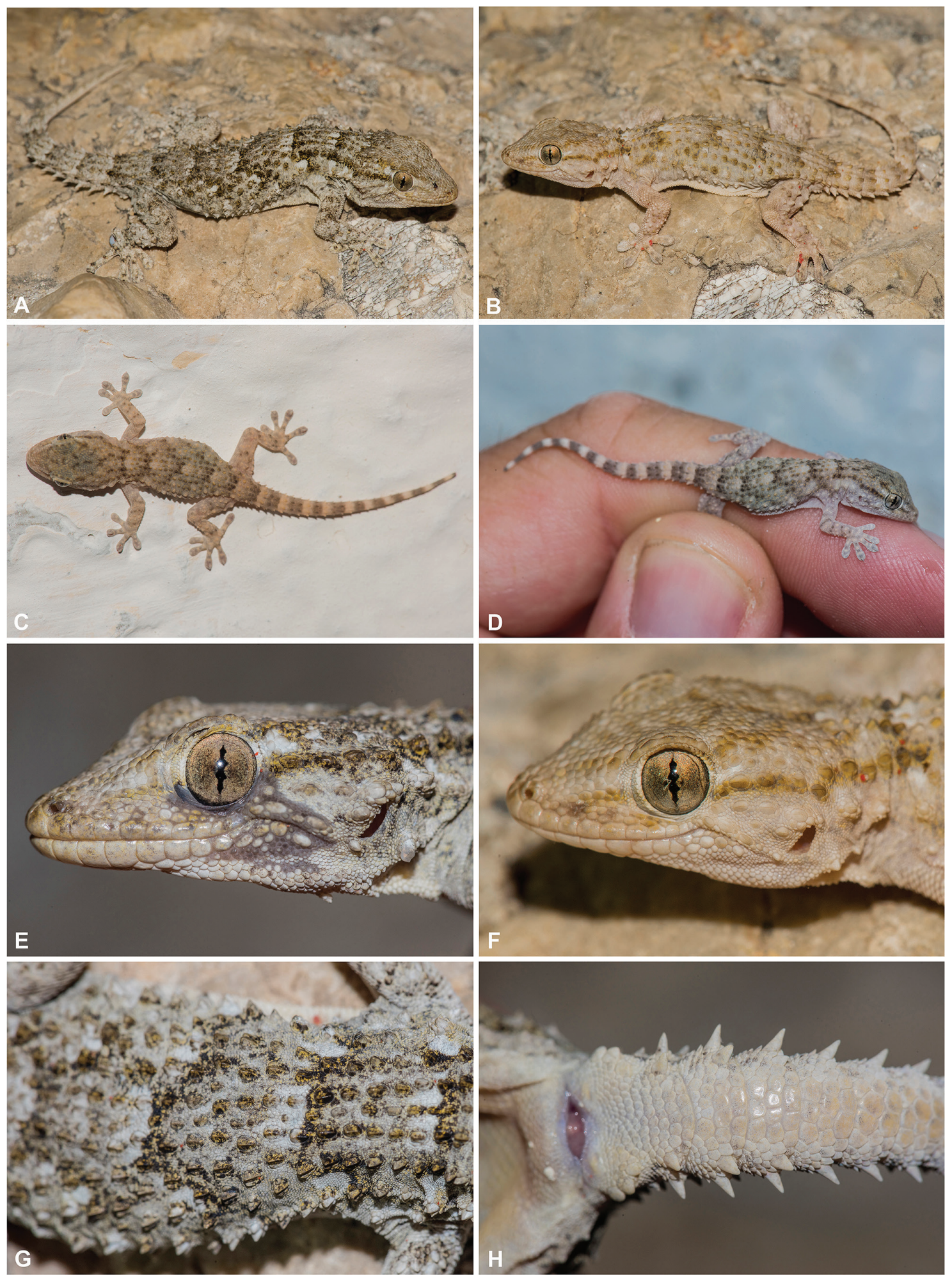

Figure 3. A. Adult male of Tarentola mauritanica from Vlorë, Albania; B. adult female; C., D. Juveniles; E. Detailed view on the head of the adult male; F. Detailed view on the head of the adult female; G. Detail on the dorsal pattern and scalation of the adult male; $\mathbf{H}$. Detail on the scalation in the base of the tail.

dense vegetation made from ruderal plants and some fig trees. It is located in an urbanised area close to the sea $\left(40.4537^{\circ} \mathrm{N}, 19.4816^{\circ} \mathrm{E}\right)$. Subsequent fieldwork from 10 August 2019 (one night) showed the presence of the species in surrounding streets and their buildings. We searched the area by looking mostly at the walls, but also into holes, crevices and trees, both day and night. Geckos were easily detectable every time from a few metres. We did not estimate the population size, but we observed several individuals (up to 40 in a couple of hours) of both sexes and all age stages (Fig. 3A-G) suggesting the population is well established and reproducing. The area is also inhabited by Podarcis muralis, H. turcicus and Bufotes viridis. 
Tarentola mauritanica is very prone to be introduced, often lives in cities and can be picked up accidentally with cargo. Most, if not all, of the populations in the Balkans are of foreign origin what is suggested also by DNA analysis (Harris et al. 2004). We did not perform a genetic analysis to confirm that because it is hard to trace the exact origin of introduction with often-used molecular-phylogenetic analyses (Mačát et al. 2014). However, it may be possible with a larger scale database on more variable genetic markers, such as microsatellites (Molecular Ecology Resources Primer Development Consortium et al. 2013). Tarentola mauritanica populations in the eastern part of the Mediterranean area (e.g. Crete or Corfu Island, Greece) belong to a single phylogenetic clade (Europe/North Africa; Mačát et al. 2014, Rato et al. 2016), thus we assume this new population also belongs there. The coast of Italy, where the species is present, is distanced only $90 \mathrm{~km}$ from the Vlorë port and, because the maritime connection is well established between Albania and Italy, we can expect such species origin in Albania. It would, therefore, be important to conduct further field research also in other busy international ports of Albania, such as Durrës or Sarandë.

Currently, there is no barrier for the species to spread in the area of Vlorë and Albania and this can be a conservation issue in the future, but also an interesting new research topic along with the investigation of other presumably newly-established populations, for example, in Greece (Mačát et al. 2014, Strachinis et al. 2020). It can also have effects on local invertebrates as the main prey source and on herpetofauna, most likely competition with H. turcicus as observed by Lisičić et al. (2012).

\section{Acknowledgements}

We thank Jana Christophoryová, Simona Papežíková and Petr Papežík for their help during the fieldwork. The study was supported by the Slovak Research and Development Agency under contract no. APVV-19-0076.

\section{References}

Bruno S (1989) Introduction to a study of the herpetofauna of Albania. British Herpetological Society Bulletin 29: 16-41.

Džukić G, Kalezić ML (2004) The biodiversity of amphibians and reptiles in the Balkan Peninsula. In: Griffiths HI, Kryštufek B, Reed JM (Eds) Balkan Biodiversity: Pattern and Process in the European Hotspot. Kluwer Academic Publishers, Dordrecht, 167-192. https://doi.org/10.1007/978-1-4020-2854-0_10
Harris DJ, Batista V, Lymberakis P, Carretero MA (2004) Complex estimates of evolutionary relationships in Tarentola mauritanica (Reptilia: Gekkonidae) derived from mitochondrial DNA sequence. Molecular Phylogenetics and Evolution 30(3): 855-859. https://doi. org/10.1016/S1055-7903(03)00260-4

Krofel M, Cafuta V, Planinc G, Sopotnik M, Šalamun A, Tome S, Vamberger M, Žagar A (2009) Distribution of reptiles in Slovenia: a review of data collected until 2009. Natura Sloveniae 11(2): 61-99.

Lisičić D, Drakulić S, Herrel A, Đikić D, Benković V, Tadić Z (2012) Effects of competition on habitat utilization in two temperate climate gecko species. Ecological Research 27: 551-560. https://doi. org/10.1007/s11284-011-0921-5

Ljubisavljević K, Tomović L, Urošević A, Gvozdenović S, Iković V, Zagora V, Labus N (2018) Species diversity and distribution of lizards in Montenegro. Acta Herpetologica 13(1): 3-11. https://doi. org/10.13128/Acta_Herpetol-21327

Mačát Z, Starcová M, Červenka J, Jablonski D, Šandera M (2014) A molecular assessment and first record of Tarentola mauritanica (Squamata: Phyllodactylidae) on Corfu, Greece. Salamandra 50(3): 172-176.

Mizsei E, Jablonski D, Végvári Z, Lengyel S, Szabolcs M (2017) Distribution and diversity of reptiles in Albania: a novel database from a Mediterranean hotspot. Amphibia-Reptilia 38(2): 157-173. https://doi.org/10.1163/15685381-00003097

Molecular Ecology Resources Primer Development Consortium et al. (2013) Permanent Genetic Resources added to Molecular Ecology Resources Database 1 December 2012-31 January 2013. Molecular Ecology 13(3): 546-549. https://doi.org/10.1111/17550998.12095

Rato C, Harris DJ, Carranza S, Machado L, Perera A (2016) The taxonomy of the Tarentola mauritanica species complex (Gekkota: Phyllodactylidae): Bayesian species delimitation supports six candidate species. Molecular Phylogenetics and Evolution 94: 271-278. https://doi.org/10.1016/j.ympev.2015.09.008

Speybroeck J, Beukema W, Bok B, Van Der Voort J, Velikov I (2016) Field Guide to the Amphibians and Reptiles of Britain and Europe. Bloomsbury Publishing, London, 432 pp.

Strachinis I, Paterekas N, Tzoras E (2020) Tarentola mauritanica (Squamata: Phyllodactylidae) conquering the Greek mainland: three new populations from Aetoloakarnania, Western Greece. Russian Journal of Herpetology 27(3): 175-178. https://doi.org/10.30906/10262296-2020-27-3-175-178

Szabolcs M, Mizsei E, Jablonski D, Vági B, Mester B, Végvári Z, Lengyel S (2017) Distribution and diversity of amphibians in Albania: new data and foundations of a comprehensive database. Amphibia-Reptilia 38(4): 435-448. https://doi. org/10.1163/15685381-00003126

Tomás-Vives P (2015) Management plan for Sazan Island, Albania. PIM Initiative, Report to the Conservatoire du littoral, $99 \mathrm{pp}$. 